\title{
Afetos e memórias: a trajetória de Maria Clara Tomaz Machado em perspectiva
}

\author{
Artur Nogueira Santos e Costa ${ }^{1}$
}

\begin{abstract}
RESUMO:
Este texto foi escrito para ser apresentado no Seminário "Clareando caminhos: cultura popular, memórias e identidades no fazer acadêmico", realizado na Universidade Federal de Uberlândia, em novembro de 2018, em homenagem à professora Maria Clara Tomaz Machado em razão de sua aposentadoria. Discuto elementos da trajetória de Maria Clara a partir da leitura de sua produção intelectual, com foco na questão do ofício do historiador, do patrimônio cultural e da cultura popular.

Palavras-Chave: Trajetória profissional. Memórias. Ofício do historiador.
\end{abstract}

\begin{abstract}
:
This text was written to be presented at the Seminar "Clearing ways: Popular Culture, Memories and Identities in Academic Achievement", held at the Federal University of Uberlândia, in November 2018, in honor of the teacher Maria Clara Tomaz Machado due to her retirement. I discuss elements of Maria Clara's trajectory from the reading of her intellectual production, focusing on the question of the office of historian, cultural heritage and popular culture.
\end{abstract}

Keywords: Professional trajectory. Memoirs. Office of the historian.

É do tecido social entramado pelas injustiças e glórias, pelas paixões e incertezas, pelas resistências e conformismos, pela dor e violência que o poeta e o historiador se servem. A história, assim como o canto, não pode ser uma traição à vida e, é claro que, para o historiador comprometido com a transformação social, só é justo historiar se nossa história arrasta consigo a voz daqueles que jamais puderam se expressar. Poderíamos afiançar ao poeta que, se o alimento para o seu canto é o momento intensamente vivido, para o historiador o passado só tem sentido quando o seu presente o instiga a visitá-lo.

Maria Clara Tomaz Machado

1 Professor no Instituto de Ciências Humanas, curso de História, da Universidade Federal de Uberlândia. E-mail: artur@ufu.br 
Escrevo este texto num momento peculiar. Nesses últimos anos, como historiadores/as de formação, assistimos perplexos/as "à reorganização e ao fortalecimento político das direitas", com uma sensação de desesperança, de assolamento e de catástrofe, com os sucessivos momentos que compuseram o Golpe de 2016 e seus desdobramentos. (GALLEGO, 2018; JINKING, DORIA, CLETO, 2016)

Vivenciamos, na mais recente história do Brasil, diferentes disputas em torno das eleições presidenciais, em 2018, que acirraram a polarização política e nos colocaram de frente com a necessidade de enfrentar um presidente eleito cujos princípios se alimentam do fascismo, da violência e do desrespeito pela democracia.

Esse processo tornou ainda mais explícito um movimento que, há algum tempo, marca a agenda social do país: o ataque às universidades públicas, à docência, ao pensamento crítico e, especialmente, ao fazer historiográfico. Por um lado, esse conjunto de elementos, em alguma medida, tem nos arrefecido ou paralisado. Por outro lado, a trajetória e a produção intelectual de Maria Clara Tomaz Machado - mulher, historiadora, professora -, da qual quero falar agora, vão na contramão dessa corrente: reativam nossa esperança, aguçam nossa sensibilidade e nos fazem crer que é necessário ter coragem e resistir, lutar pelo que defendemos e escolher de que lado da trincheira queremos estar. Portanto, sua merecida aposentadoria, com uma história cheia de méritos e depois de árduo trabalho, é motivo para celebrar.

Nesse sentido, proponho, aqui, retomar alguns elementos dessa sua trajetória. Devo dizer que os recortes que estabeleci foram operados pela minha ótica e pela minha experiência, e não seguem uma linearidade. Então, e não poderia ser diferente, são permeados de admiração e de respeito pela sua prática profissional, que sempre foi corajosa, ousada e viva, sempre nos fez sair dos lugares cômodos. Por isso, revirando as memórias que deram um fio condutor a esse texto, penso que encontrei 
aquele sentido de combate ao conformismo apontado por Walter Benjamin (2012). Maria Clara é inspiração para isso.

Como ponto de partida, recordo uma experiência que vivi imediatamente após ingressar no curso de História, em 2010. Na primeira semana de aulas, fomos a uma visita guiada na biblioteca da universidade, para aprender como a mesma funcionava, sobre como poderíamos acessá-la ou como sua base de dados estava organizada. Num determinado momento da visita, a Técnica nos ensinava como é que se fazia consultas ao acerco a partir do nome dos/as autores/as que desejássemos encontrar. E completou: "Já que a turma é do curso de História, vamos usar como exemplo uma autora do próprio curso." Então, na ferramenta de busca do acervo da biblioteca, projetada pelo datashow, digitou: Maria Clara Tomaz Machado. Nós, recém ingressos na universidade, ficamos vaidosos com aquela situação. Pensávamos: "poxa, temos uma professora que é também autora de livros e conhecida até pela moça da biblioteca, que legal!”.

Talvez, essa seja minha primeira memória marcante quanto ao curso. Lembro-me com frescor do livro que a referida técnica escolheu para nos exemplificar: "Caminho das pedras: inventário temático de fontes documentais. Uberlândia - 1900/1980”, que Maria Clara organizou junto com Valéria Lopes. Trata-se de um catálogo que sintetiza as principais fontes para pesquisa sobre a história local, passando por temas como "classe trabalhadora", "discursos e práticas políticas", "gênero", "educação" e outros. A obra, escrita coletivamente, demonstra a constante preocupação de Maria Clara com a história de Uberlândia, a qual, para ela, deve ser tratada de modo a desfazer o discurso da ordem e do progresso forjado pelas elites da cidade.

O primeiro capítulo de "Caminho das pedras", redigido por ela, se intitula "Do silêncio dos arquivos às pluralidades das vozes: histórias locais e regionais", no qual a autora reafirma sua posição de que o ofício do/a historiador/a requer posicionamento político e compromisso com a transformação social. O referido texto, que, nos últimos dez anos, constituiu 
uma das leituras básicas de gerações de estudantes do curso de graduação em história, nos ensina várias lições com relação à nossa prática profissional. Para começar, de acordo com suas palavras, é tarefa do/a historiador/a questionar

[...] a produção historiográfica até hoje recheada de heróis reminiscentes de uma classe social poderosa economicamente e que, enquanto dominante, permitiu que personagens expropriados e despossuídos ocupassem o papel de coadjuvantes [...]. (MACHADO, 2007, p. 10)

Por esse viés, ela afirma sua compreensão da história como um saber em que tem lugar não só os grandes nomes, os heróis, aqueles que venceram, mas também os que foram silenciados, os que foram banidos da cena, os que lutaram e nem sempre conseguiram a vitória. Num explícito diálogo com Benjamin, Maria Clara constantemente insiste nessa dimensão de nosso ofício. Tanto nos seus textos como em suas aulas, enfatizava a necessidade de nos atentarmos para quais sujeitos históricos ganham destaque em nossas narrativas e nos provocava a desconfiar dos discursos prontos, bem arquitetados pelas classes dominantes, mas recheados de fissuras e contradições que, para ela, deveriam ser inquiridos, interrogados e confrontados.

Sua preocupação com a história local e com as muitas histórias de Uberlândia lhe rendeu convites para fazer diversas palestras, na universidade e fora dela, oportunidades nas quais Maria Clara fazia questão de destacar a variedade de documentos com os quais os/as interessados/as pela temática poderiam lidar. Conhecia as Atas da Câmara Municipal de Uberlândia, coleções fotográficas, conjuntos documentais da ICASU, entre outros - materiais que, em sua compreensão, devem ser explorados não pelo que trazem de mais visível, mas pelos seus silêncios, seus não ditos, suas ambiguidades, capazes de colocar em cena os "desertores": os leprosos, os mendigos, as prostitutas, os jogadores, os vagabundos e tantos outros subversivos ao ideário plantado pela vontade burguesa. 
Com relação a essa temática, cabe mencionar sua dissertação de mestrado, pioneira na problematização da cidade de Uberlândia e da memória constituída sobre ela. Com o título "A disciplinarização da pobreza no espaço urbano burguês: assistência social institucionalizada. (Uberlândia 1965-1985).", a maior parte dos trabalhos que a sucederam a tomou por referência indispensável.

Com essa preocupação presente em toda a sua atuação profissional, como professora dos cursos de graduação em História e do Programa de PósGraduação em História, Maria Clara foi peça fundamental para criação do Centro de Documentação e Pesquisa em História, o CDHIS, que abriga coleções documentais de variadas naturezas que constituíram a base de incontáveis pesquisas de graduação, de mestrado e de doutorado. Nesse sentido, ainda na década de 1980, Maria Clara, com outros/as professores/as, batalhou para conseguir, junto à universidade e ao poder público, um espaço para o que viria a se transformar no CDHIS, lutou para conseguir as coleções documentais, para constituir a organicidade que compõe a estrutura do acervo e para que ele se consolidasse como espaço efetivo de pesquisa em história.

Nos primeiros períodos do curso de graduação em História, quando ministrava as disciplinas Introdução aos Estudos Históricos ou Projeto Integrado de Práticas Educativas, não abria mão de levar os/as estudantes ao CDHIS e também ao Arquivo Público Municipal de Uberlândia, como meio de, desde o início, colocá-los em contato com documentos e incentivar a pesquisa como dimensão fundamental da formação de historiadores/as.

Nessa ótica da preocupação com a formação de historiadores/as, outro debate que sempre esteve presente nas discussões protagonizadas por Maria Clara Tomaz Machado é a questão do patrimônio cultural. Ela sempre batalhou para que a reflexão sobre os sentidos de patrimônio, suas nuances políticas e os interesses que revela fossem incorporadas ao processo formativo, nos cursos de história, para munir os futuros egressos de elementos que os habilitassem a atuar também nessa seara. De modo 
coerente como o que já foi levantado, Maria Clara se contrapõe a uma noção de patrimônio como algo estático, congelado no tempo, esvaziado de significados no presente. Pensa patrimônio histórico e cultural como dimensão constitutiva da memória social de muitos e diferentes sujeitos. Em suas palavras:

O problema que trago para o debate não é o da necessidade de uma lei oficial, que, sem dúvida, pode trazer dividendos que contemplem a preservação de práticas culturais populares, até então anônimas. O que de fato me incomoda é que nos debates travados sobre Patrimônio Cultural, mesmo reconhecendo o importante papel dos órgãos oficiais ligados ao Ministério da Cultura e às secretarias estaduais e municipais que nos assessoram [...]; mesmo reconhecendo que os intelectuais de qualquer nível são necessários para garantir a história, e a função social do bem cultural tombado - por que será que grande parte da comunidade interessada fica alheia às diversas discussões travadas sobre o tema? (MACHADO, 2011, p. 43-44)

E complementa:

[...] não seríamos nós da academia que deveríamos nos aproximar do caipira que ponteia sua violinha e compartilhar com ele sua fala, seus desejos, sonhos, utopias, na preservação de seu passado? (MACHADO, 2011, p. 44)

Assim, na fala da historiadora, o que se percebe, mais uma vez, é a preocupação de trazer para a cena os diversos grupos que são constitutivos do social. Para Maria Clara, debater patrimônio do ponto de vista oficial, formular leis e tombar prédios, apesar de importante, nunca foi suficiente. No seu dizer, é necessário incorporar o olhar dos sujeitos, seus modos de vida, suas angústias como dimensões capazes de atribuir sentidos para o patrimônio. Como sempre enfatizou em seus textos e em suas aulas, a história é bonita porque fala da vida, porque lida com a gente comum que sofre, luta, perde, vence, se acomoda, protesta, canta, festeja. 
Essa densa articulação entre saber histórico, patrimônio, memória e as gentes como sujeitos da história se expressa também em "São Marcos do Sertão Goiano: cidades, memória e cultura", que Maria Clara organizou junto com Cairo Katrib e Mônica Abdala, dois de seus grandes parceiros acadêmicos. A obra é resultado de projeto coletivo que coordenou, reunindo pesquisadores de diferentes níveis formativos: alunos/as de graduação, de mestrado, de doutorado, professores/as universitários, cujo objetivo foi colocar em pauta as histórias e memórias dos/as moradores/as do entorno do Rio São Marcos, em Goiás, região afetada pela construção da barragem da Usina Hidrelétrica Serra do Facão.

Publicada em 2010, reúne artigos que contextualizam a região, que falam sobre a transformação das paisagens, sobre as festas, os sons, os hábitos alimentares, as fés e as devoções dos/as moradores/as, apontando a preocupação do grupo com as tramas que sustentaram os diversos modos de vida desses sujeitos e com suas práticas culturais capazes de produzir sentidos (re)inventados cotidianamente. (MACHADO, KATRIB, ABDALA, 2010)

O artigo que abre a coletânea, de autoria de Maria Clara, é proposital para prosseguir com essa reflexão sobre como ela compreende a história e o seu fazer acadêmico. Refletindo sobre a experiência de pesquisa e sobre os dados levantados, afirma:

[...] ao inventariar o patrimônio histórico-cultural das pessoas e lugares afetados pela construção da hidrelétrica Serra do Facão, pretendemos apreender, por meio das memórias e práticas culturais de seus moradores, não só a sua história, mas, sobretudo, esse momento muito especial de perdas, resistências, reencontros e deslocamentos sociais que, na verdade, tal como afirma Guimarães Rosa, são também travessias, muitas vezes perigosas, mas parte da própria vida, da própria história. (MACHADO, 2010, p. 26)

Além de sustentar novamente seu compromisso com a memória dos que não foram contemplados na narrativa oficial, Maria Clara nos ensina, de modo poético, uma importante lição: a de pensar a história como campo conflituoso, não linear, marcado por avanços e retrocessos, conquistas e 
perdas. Assim como no trecho, suas falas durante as aulas, nas palestras que proferiu ou nas bancas de mestrado e doutorado sempre colocavam como alerta a necessidade de encarar o contraditório e de fugir da armadilha do progresso. A menção a Guimarães Rosa não é mera coincidência. Paradoxalmente, sua escrita consegue, como poucas, condensar densidade e leveza, ao mesmo tempo. A tônica de seus textos carrega a poesia, de um lado, e a minúcia historiográfica, de outro. Aliadas com a riqueza de suas referências teóricas, sempre dialogou com a literatura, com a música e com as demais expressões artísticas.

Por falar em poesia, vale lembrar do artigo "(Re)significações culturais no mundo rural mineiro: o carro de boi - do trabalho ao festar (1950-2000)”, publicado na Revista Brasileira de História, em 2006, no qual afirma:

A mineiridade não se esgota com os políticos matreiros, com os poetas de belas falas ou com sua decantada hospitalidade. O rubro sangue de índios exterminados e o suor do trabalho escravo entremeados à terra tingiram o seu solo de ferrugem e nódoa.

Dos espaços, guarda confrontos de paisagens: das minas, as montanhas, o ouro encravado em fendas seculares, desvendado pelos colonos portugueses. Das Gerais, o horizonte infinito, vales e rios escorregadios sertão - por onde pastagens e fazendas se foram fazendo, obra de bandeirantes e pioneiros em busca de riquezas e com raízes por fincar. (MACHADO, 2006, p. 26)

Suas palavras são inegavelmente poéticas, mas, nem por isso, destituídas de oportuna sagacidade. Falando de Minas Gerais, Maria Clara nos revela, na verdade, o que é o Brasil. Descortina o mito da "cordialidade" ou da "hospitalidade", como diz ela, para dizer que nossa terra é marcada também por violência. Nossas belas paisagens foram palco de extermínio de incontáveis etnias indígenas e nosso solo foi tingido pelas marcas indeléveis da escravidão. Junto à menção à nossa geografia, lembra que a ação dos 
bandeirantes ávidos por riquezas deu contornos aos caminhos que seguimos, o que tem tudo a ver com a estrutura de sociedade que temos, no presente.

Mas a poesia de suas palavras está também no modo como interpreta os usos do carro de boi, sobre o que aponta:

À parte a sua utilidade, no que se refere ao translado de mercadorias e gêneros de primeira necessidade, existe à sua volta toda uma construção do imaginário popular que vai desde o seu cantar, até os "causos" dos bois de estimação e da fama que envolve o carreiro "bom de serviço". Os bois recebem codinomes, que por si só explicitam sua função: Desengano, Desafio, Mestiço, Lobisomem, Soberano, Malhado, Chibante, Brioso. A sincronia entre boi e carreiro é cantada em verso e prosa [...]. (MACHADO, 2006, p. 30)

Interpretando essas práticas, a autora estabelece um elo entre campo e cidade, e demonstra como as relações de trabalho eram mais complexas do que poderiam parecer. Além disso, como de costume, marca a crítica a uma realidade no campo permeada por relações clientelistas e paternalistas, ainda na década de 1950. Com seu olhar arguto de historiadora, Maria Clara percebe os entremeios do cotidiano daquelas pessoas, caracterizado por uma rede de saberes e tarefas que desafiavam as imposições dominantes.

Sempre atenta às nuances vivenciadas pelos sujeitos, conclui que, ainda que atropelados pelas tentativas de "desenvolvimento" e de "progresso" típicas da ordem burguesa, ou pelas práticas desintegradoras de experiências de vida do capitalismo liberal, são capazes de resistir e de reinventar uma tradição. A festa do carro de boi, realizada da região do Triângulo Mineiro, é exemplo desse movimento em que se articulam o simbólico, o lúdico e o religioso, num processo em que as gentes comuns escrevem e reescrevem a história das muitas Minas Gerais.

Maria Clara forjou uma abordagem peculiar para pensar a cultura popular. Por isso, se tornou referência nacional nos debates desse campo. Em suas reflexões, nunca abriu mão de refletir sobre o social. Propunha 
interpretar a cultura popular como algo que está próximo a nós, nos rituais, nas simbologias, nas religiosidades e nas contradições sociais, na musicalidade e nos ritmos que contornam e constituem os nossos modos de viver. Ao mesmo tempo, sempre advertiu para o fato de que todas essas dimensões se forjam numa sociedade capitalista, marcada pela desigualdade e pela exploração, o que não deve passar despercebido pelo nosso olhar. (MACHADO, 1994)

$\mathrm{Na}$ construção dessa compreensão, dialogou com uma gama extremamente variada de autores para se contrapor a uma noção de cultura popular como subalterna, inferior. Leitora de Ginzburg e de Bakhtin, pensava as múltiplas dimensões culturais como campos relacionais, cingidos por influxos recíprocos. Na esteira da cultura popular, pesquisou e orientou pesquisas sobre música, festas, práticas de devoção, religiosidade. Sua tese de doutorado, defendida na Universidade de São Paulo (USP) em 1998, deu corpo a essa série de inquietações, aliando sensibilidade e rigor teórico na interpretação das práticas culturais nos rincões de Minas Gerais.

Mais recentemente, Maria Clara se dedicou aos estudos sobre vídeo documentários e história, com a criação do DOCPOP (Laboratório de Cultura Popular e Vídeo Documentário), no âmbito do Instituto de História da UFU, que coordenou até meados de 2018. Sobre essa temática, orientou pesquisas de Iniciação Científica, organizou oficinas, produziu seminários e, especialmente, coordenou a produção de algumas películas, como "Sertão de dentro: travessias e veredas em Goiás", "De Grande Otelo para Sebastião" e “Agô, Minha Mãe”, das quais sempre fala com orgulho.

$\mathrm{Na}$ releitura de todos esses textos, é digna de nota a variedade de autores com que Maria Clara dialoga. Ao contrário de muitos/as, que se enquadram em esquematismos e dogmatismos redutores, seus trabalhos se utilizam de diferentes campos conceituais e teóricos. Só para citar alguns: Karl Marx, Roger Chartier, Raymond Williams, E. P. Thompson, Ecléa Bosi, Stuart Hall, Antônio Cândido, Sérgio Buarque de Holanda, Eric Hobsbawm, 
Michel Foucault, Pierre Bordieu, Homi Bhabha, Carlo Ginzburg e, é claro, não poderia faltar, Michel de Certeau.

Uma outra memória marcante que penso ser importante recordar se refere ao momento de sua defesa de memorial para progressão na carreira do magistério superior, quando se tornou Professora Titular. Na oportunidade, a professora Maria Helena Capelato, da USP, que presidia a banca examinadora, afirmou: "você, Maria Clara, é uma autoritária doce". Essa expressão vem muito a calhar...

Do ponto de vista profissional, Maria Clara manteve, ao longo dos anos em que atuou na UFU, uma postura firme e profundamente autêntica. Meias palavras não fazem muito o seu tipo. É bem verdade que, quando quer, pode ser um "trator", daqueles que atropela tudo o que estiver à sua frente. Defende com conviç̧ão seus pontos de vista e, não raro, dá broncas: “vá ler o texto direito, menino!". Mas, como bem enfatizou Capelato, Maria Clara é de uma rara generosidade. Formou e orientou gerações de historiadores/as que, hoje, atuam em diferentes instituições pelo país. Mas não se trata de uma orientação qualquer: é profundamente afetuosa, cuidadosa e atenciosa. Empresta pilhas de livros e diz: "vou anotar na minha agenda e, se não devolver, vou na sua casa buscar.” É daquelas que acolhe, como mãe, mesmo os filhos que são postiços, como eu, que não fui seu orientando. É daquelas que destrói falsas certezas e caminha junto, na construção de bases mais sólidas. É generosa porque, como artesã experiente, partilha com os seus a sabedoria sobre o tecer da história. Merecidamente, Maria Clara se aposentou, mas sua capacidade de fazer da história um espaço de acolhimento e de luta continuará a oxigenar nosso pensar acadêmico e social, a alimentar nossa ousadia e a nos fazer crescer, sempre.

Obrigado por ser você, Maria Clara.

\section{Referências}


BENJAMIN, Walter. Sobre o conceito da história. In: Magia e técnica, arte e política: ensaios sobre literatura e história da cultura. 8. ed. São Paulo: Brasiliense, 2012. p. 241-252.

GALLEGO, Esther Solano. $O$ ódio como política: a reinvenção das direitas no Brasil. São Paulo: Boitempo, 2018.

JINKINGS, Ivana; DORIA, Kim; CLETO, Murilo (orgs.). Por que gritamos golpe?: para entender o impeachment e a crise política no Brasil. São Paulo: Boitempo, 2016.

MACHADO, Maria Clara Tomaz. "(Re)significações culturais no mundo rural mineiro: o carro de boi - do trabalho ao festar (1950-2000). Revista Brasileira de História. São Paulo, v. 26, nº 51, p. 25-45 - 2006.

A disciplinarização da pobreza no espaço urbano burguês: assistência social institucionalizada. (Uberlândia 1965-1985). 1990. Dissertação (Mestrado em História). Universidade de São Paulo, São Paulo, 1990.

Cultura popular - em busca de um referencial conceitual. Cadernos de História. Uberlândia, v. 5, n. 5, p. 73-83, jan./dez. 1994.

Do silêncio do arquivo às pluralidades das vozes: histórias locais e regionais. In:___ _ LOPES, Valéria Maria Queiroz Cavalcante. Caminho das pedras: inventário temático de fontes documentais. Uberlândia 1900/1980. Uberlândia: EDUFU, 2007. p. 9-15.

Patrimônio cultural/(in)certezas: interesses políticos, para quem e o que preservar? In: PATRIOTA, Rosangela; CARDOSO, Heloísa Helena Pacheco. Escritas e narrativas históricas na contemporaneidade. Belo Horizonte: Fino Traço, 2011. p. 41-50.

Serra do Facão: na encruzilhada dos sertões. In: MACHADO, Maria Clara Tomaz; KATRIB, Cairo Mohamad Ibraim; ABDALA, Mônica Chaves. São Marcos do Sertão Goiano: cidades, memória e cultura. Uberlândia: Edufu, 2010. p. 23-27.

; KATRIB, Cairo Mohamad Ibraim; ABDALA, Mônica Chaves. Contornos do vivido: travessias, histórias e memórias na área da usina hidrelétrica Serra do Facão. In: São Marcos do Sertão Goiano: cidades, memória e cultura. Uberlândia: Edufu, 2010. p. 15-20.

; KATRIB, Cairo Mohamad Ibraim; ABDALA, Mônica Chaves. São Marcos do Sertão Goiano: cidades, memória e cultura. Uberlândia: Edufu, 2010 .

Recebido em fevereiro de 2019.

Aprovado em abril de 2019. 